\title{
RELAÇÕES ÉTNICO-RACIAIS E SABERES DOCENTES NA ESCOLA DE EDUCAÇÃO INFANTIL DA UNIVERSIDADE FEDERAL DO RIO DE JANEIRO
}

\author{
RELACIONES ÉTNICO-RACIALES Y SABERES DOCENTES EN LA ESCUELA DE \\ EDUCACIÓN INFANTIL DE LA UNIVERSIDAD FEDERAL DE RÍO DE JANEIRO
}
ETHNO-RACIAL RELATIONS AND TEACHING KNOWLEDGE AT THE SCHOOL OF EARLY CHILDHOOD EDUCATION OF THE FEDERAL UNIVERSITY OF RIO DE JANEIRO

\author{
Edmilson dos Santos FERREIRA ${ }^{1}$ \\ José Jairo VIEIRA ${ }^{2}$ \\ Andréa Lopes da Costa VIEIRA ${ }^{3}$
}

RESUMO: Este trabalho tem por objetivo identificar as estratégias adotadas na prática docente em Educação Infantil, considerando a construção de um princípio pautado no diálogo, que priorize a pesquisa com criança. Os conceitos de saberes docentes e diversidade são eixos temáticos que se articulam com a Sociologia da Infância que se apresentam como uma linha orientadora do projeto pedagógico de uma creche universitária de Educação Infantil localizada no Rio de Janeiro. Nesse sentido, os estudos iniciaram com as seguintes questões: quais são as práticas pedagógicas desenvolvidas com as crianças que envolvem as temáticas: diversidade e relações étnico-raciais na Educação Infantil? Tais práticas procuram estabelecer o diálogo com a Educação das relações étnico-raciais? Para orientação metodológica deste estudo, optamos por uma abordagem qualitativa de pesquisa e análise documental como sendo a estratégia privilegiada de coleta dedados. A pesquisa aponta para a valorização das relações étnico-raciais e uma demanda por encontros de formação continuada que potencializem os grupos de estudos e trocas de experiências.

PALAVRAS-CHAVE: Infância. Relações étnico-raciais. Creche universitária. Educação infantil.

RESUMEN: Este trabajo tiene por objetivo identificar las estrategias adoptadas en la práctica docente en Educación Infantil, considerando la construcción de un principio

\footnotetext{
${ }^{1}$ Universidade Federal do Rio de Janeiro (UFRJ), Rio de Janeiro - RJ - Brasil. Doutorando do Programa de PósGraduação em Educação. Integrante do Laboratório do Pesquisa em Movimentos Sociais, Desigualdades e Diversidades de Corpo, Raça e Gênero (LADECORGEN/UFRJ). OrcID: http://orcid.org/0000-0003-2561-7915. E-mail: edmilsf@gmail.com

${ }^{2}$ Universidade Federal do Rio de Janeiro (UFRJ), Rio de Janeiro - RJ - Brasil. Professor do Programa de PósGraduação em Educação. Coordenador do Laboratório do Pesquisa em Movimentos Sociais, Desigualdades e Diversidades de Corpo, Raça e Gênero (LADECORGEN/UFRJ). OrcID: http://orcid.org/0000-0002-9395-5345. E-mail: desigualdade.diversidade.educa@gmail.com

${ }^{3}$ Universidade do Estado do Rio de Janeiro (UNIRIO), Rio de Janeiro - RJ - Brasil. Professora do Programa de Pós-Graduação em Memoria Social. Professora do Programa de Pós-Graduação em Educação da Universidade Federal do Rio de Janeiro (PPGE-UFRJ). Pesquisadora do Laboratório do Pesquisa em Movimentos Sociais, Desigualdades e Diversidades de Corpo, Raça e Gênero (LADECORGEN/UFRJ). OrcID: http://orcid.org/00000002-3672-6298. E-mail: andrea.lcosta@uol.com.br
} 
pautado en el diálogo, que priorice la investigación con niños. Los conceptos de saberes docentes y diversidad son ejes temáticos que se articulan con la Sociología de la Infancia que se presentan como una línea orientadora del proyecto pedagógico de una guardería universitaria de Educación Infantil ubicada en Río de Janeiro. En ese sentido, los estudios comenzaron con las siguientes cuestiones: ¿cuáles son las prácticas pedagógicas desarrolladas con los niños que envuelven las temáticas: diversidad y relaciones étnicoraciales en la Educación Infantil? ¿Tales prácticas tratan de establecer el diálogo con la Educación de las relaciones étnico-raciales? Para orientación metodológica de este estudio, optamos por un abordaje cualitativo de investigación y análisis documental como la estrategia privilegiada de recolección de huellas. La investigación apunta a la valorización de las relaciones étnico-raciales y una demanda por encuentros de formación continuada que potencien los grupos de estudios e intercambios de experiencias.

PALABRAS CLAVE: Infancia. Relaciones étnico-raciales. Guardería universitaria. Educación infantil.

ABSTRACT: This work aims to identify strategies adopted in teaching practice in Early Childhood Education, considering the construction of a principle based on dialogue, which prioritize research with children. The concepts of teaching knowledge and diversity are thematic axes that are articulated with the Sociology of Childhood, which are presented as a guideline of the pedagogical project of a nursery school of Child Education located in Rio de Janeiro. In this sense, the studies began with the following questions: what are the pedagogical practices developed with children that involve the themes: diversity and ethnicracial relations in Early Childhood Education? Do such practices seek to establish dialogue with the Education of ethnic-racial relations? For the methodological orientation of this study, we opted for a qualitative approach of research and documentary analysis as the privileged strategy of collecting fingerprints. The research points to the valorization of ethnic-racial relations and a demand for meetings of continuous formation that potentiate the groups of studies and exchanges of experiences.

KEYWORDS: Childhood. Ethnic-racial relations. University day care. Early childhood education.

\section{Introdução}

No Brasil, a partir da Lei de Diretrizes e Bases da Educação - LDB/96, a Educação Infantil se constituiu como a primeira etapa da Educação Básica, promovendo uma maior visibilidade para as crianças de zero aos seis anos de idade, reconhecendo-as como sujeito de direitos, abrangendo as suas históricas funções assistencialistas para uma construção social das identidades infantis no contexto educacional. Nesta perspectiva, um dos principais desafios da Educação Infantil, consiste numa conversão do olhar para compreender como as crianças negras constroem as relações, expressam seus desejos, interesses e valores, nas Escolas das Infâncias. Outro desafio significativo é garantir um atendimento de qualidade que 
possibilite o desenvolvimento das crianças negras em suas múltiplas linguagens. Este artigo é parte da fase exploratória da pesquisa de doutorado em Educação, esse recorte privilegia as relações étnico-raciais na infância e os saberes docentes enquanto atores sociais na Educação Infantil.

As atuais reflexões sobre concepções de infância afirmam que as crianças negras são sujeito histórico e social, porque a infância representa um período singular e significativo da vida, portanto:

É preciso considerar a infância como uma condição da criança. O conjunto de experiências vividas por elas em diferentes lugares históricos, geográficos e sociais é muito mais do que uma representação feita por adultos sobre esta fase da vida. É preciso conhecer as representações da infância e considerar as crianças concretas, localizá-las nas relações sociais, etc., reconhecê-las como produtoras de história (KUHLMANN JR., 1998, p. 31).

Nesse sentido, a concepção de infância que defendemos representa-se pelas mudanças que ocorrem nas diferentes formas de organização da sociedade que se reúnem em classes sociais distintas no que se refere à infância e a criança.

\section{Educação das Relações Étnico-raciais na infância}

A Educação das Relações Étnico-raciais na primeira infância neste trabalho investiga especialmente, as crianças em idade pré-escolar. Iniciamos nesta análise a revisão da literatura das principais pesquisas encontradas no campo dos estudos sobre a infância e as relações étnico-raciais, a partir dos estudos coordenados pelas pesquisas de: Iolanda de Oliveira (UFF), Anete Abramowicz (UFSCAR), e Fúlvia Rosembergue (PUC-SP \& Fundação Carlos Chagas).

A tese de doutorado de Trinidad (2011) discutiu a situação de invisibilidade em que se encontram as crianças não brancas. Enquanto Clade (2013) investigou as crianças maiores entre cinco e sete anos e mostra que elas são sensíveis aos sentimentos despertados diante de situações discriminatórias e avaliam como algo "feio" ou "errado".

A tese de Piccolo (2011) defendeu a valorização das diferenças como caminho para o enfrentamento e a diminuição de práticas sociais preconceituosas, através de uma práxis que valorize processo educativo critico-emancipatório.

De acordo com Abramowicz e Oliveira (2012), a partir da década de 90 foi possível perceber que a desigualdade afeta diretamente a educação brasileira, onde está intrinsicamente ligada à cor da pele. Nesta direção, 
A pobreza impacta a criança negra de maneira mais cruel e contundente do que a criança pobre branca, já que a família negra vive com mais intensidade a desigualdade social. Mas não é só isso, a pobreza é atravessada pela raça, o que significa que a raça é também explicativa da pobreza (ABRAMOWICZ; OLIVEIRA, 2012, p. 50).

Essa dualidade entre raça e questão social está intimamente entrelaçada no discurso do preconceito de classe. Fernando Rodrigues (1995) traz uma discussão do Racismo cordial que existe no Brasil, onde as pessoas negam ter, mas demonstram em pequenas atitudes que são reforçadas porque ainda há um enraizamento da classificação racial a partir da cor da pele (ABRAMOWICZ; OLIVEIRA, 2012).

Nessa mesma dinâmica de relações raciais há um conceito contemporâneo de branquitude que para Liv Sovik é entendido como:

atributo de quem ocupa um lugar social no alto da pirâmide, é uma prática social e o exercício de uma função que reforça e reproduz instituições, é um lugar de fala para qual uma certa aparência é condição suficiente (SOVIK, 2009, p. 50).

O autor assinala que a branquitude é um ideal estético e social que valoriza a cor da pele, a fisionomia, o tipo de cabelo; onde ser branco não depende da sua cor, mas do seu status social, pois a prática branca é que conta. Por isso, é uma relação complexa, porque seu discurso está permeado de afetos, travestida muitas vezes pelo discurso da mestiçagem que nega a existência dos negros e esconde a existência de brancos, implícito no discurso de que "somos todos iguais". O que caracteriza a hegemonia de uma cultura branca e de etnia europeia, onde "o valor da branquitude se realiza na desvalorização do ser negro e ela continua sendo uma medida silenciosa de quase brancos, como dos negros" (p. 53).

O trabalho de Abramowicz \& Oliveira (2012) reconhece que crianças a partir de 4 anos conseguem perceber as nuances entre brancos e negros na sociedade e, portanto, oferece atribuições positivas e negativas sobre suas características. A diferença toma corpo, quando a sociedade ocidental institui uma norma, institui um padrão que está no outro e não em si.

Assim, a socialização que se inicia na família e se amplia com o convívio escolar, ao invés de ser uma experiência positiva no desenvolvimento da criança negra, acaba sendo um fator negativo na constituição de sua autoimagem. E o silêncio que envolve a questão racial nas diversas instituições sociais favorece que se entenda a diferença como desigualdade, como desvio, como anormalidade (ABRAMOWICZ; OLIVEIRA, 2012, p. 56).

Nesse sentido, a escola sem perceber institui a desigualdade e a diferença quando seleciona os brinquedos e observamos a ausência de bonecas negras ou simplesmente não 
explora os momentos de estranhamento que se manifestam nas suas brincadeiras. Este papel de reprodução e até mesmo criação da desigualdade e a diferença na escola termina por ser um reforço das vivencias discriminatórias que a criança negra começa a perceber e a sentir na sociedade, mesmo que isso ocorra de forma simbólica (BOURDIEU, 2012).

O preconceito existe na sociedade, no entanto, partimos de levantes positivos também. Ao mesmo tempo que o discurso racista está à tona na sociedade, o sujeito não é apenas alguém que recebe a ação, mas também são atores sociais que estão a todo momento dialogando com essa sociedade, ou seja, interfere e é interferido a todo momento.

Falar de racismo no Brasil é algo complexo, pois envolve vários setores sociais, culturais, religiosos, estéticos e de gênero, entre outros. $\mathrm{O}$ debate sobre as relações étnicoraciais e as infâncias, nos levou a refletir sobre a dimensão identitária da criança negra, enquanto uma infância silenciada na Educação Infantil. Os estudos de Abramowicz et al. (2012) afirmam que as crianças, aproximadamente, a partir dos 4-5 anos já apresentam algum tipo de conceito ou identificação racial. Além de pontuar as tensões nos processos identitários que orientam as políticas de reconhecimento, enquanto possibilidade de ressignificar as diferenças.

A Lei 10.639/03 que altera a LDB representa um avanço das reivindicações do movimento negro na educação ao tornar obrigatório o ensino da temática étnico-racial e indígena nos ensinos fundamentais e médios e favorecem a política de reconhecimento das relações raciais. Contudo, "não por acaso, essa Lei se restringe especificamente às escolas de ensino fundamental e médio: a educação infantil foi excluída: trata-se de desenlace de longo percurso histórico" (ROSEMBERG, 2012, p. 33). A análise de Fúlvia Rosemberg nos fez trazer a infância e a educação infantil para o centro do debate para discutirmos as relações étnico-raciais na educação infantil.

Os aportes da sociologia ainda privilegiarão os estudos de Guimarães $(2001 ; 2004$; 2006; 2012) e de Munanga (2012) para a compreensão histórica do racismo e a reflexão sobre o mito da democracia racial. Considerando que o Brasil foi último país do continente americano a abolir a escravidão e, logo, o preconceito racial ainda provoca reações sutis, mas que deixam marcas profundas de caráter simbólico (BOURDIEU, 2012).

Os estudos de Le Breton nos apoiarão para compreender como a relação com o corpo afeta o desenvolvimento das crianças e suas interações com o grupo. Para Le Breton (2009) a aparência apresenta e representa o sujeito, envolve o comportamento, os modos de vestir e cuidar do corpo, aspectos que revelam uma linguagem corporal simbólica que diz respeito ao pertencimento social e cultural. E se constitui também de aspectos físicos como altura, massa 
e características estéticas. O cotidiano das crianças é marcado pelo desenvolvimento de sentimentos como alegria, tristeza e angustia onde a subjetividade dos diferentes contextos enquanto lugar das emoções. O sentimento de inferioridade pode ser observado em situações que envolvem o cabelo liso, a pele clara como referencial hegemônico reproduzido pelos filmes infantis comerciais que pode conduzir a reforço de situações de negação racial.

David Le Breton valoriza as relações estabelecidas com o outro. E este representa a construção social do corpo, para o autor, é na relação com o outro que exploramos as percepções sensoriais e a linguagem. Nesse contexto, as crianças por vezes, estabelecem uma hierarquia entre pobres e ricos e usam como referência a cor da pele e se os cabelos são lisos ou cacheados.

Há uma cumplicidade das famílias sobre as atitudes racistas que podem reforçar o sentimento de inferioridade entre as crianças negras e pardas. As crianças não percebem ou não distinguem o porquê de serem preteridas nas brincadeiras e na organização das atividades de livre escolha, seu comportamento traduz em lágrimas ou em silêncio. Outrora, a reação pode ser interpretada como agressividade. Esses sentimentos expressam "uma combinação de sensações corporais, de gestos e de significados culturais apreendidos por intermédio das relações sociais" (LE BRETON, 2009, p. 113).

\section{A Educação Infantil no Brasil contemporâneo}

Dentre os caminhos possíveis para discutirmos sobre a Educação Infantil contemporâneo, optamos sobre refletir sobre a Educação Infantil como direito. Assegurar os direitos sociais, especialmente os direitos das crianças negras para que elas se desenvolvam em suas múltiplas linguagens requer proteção e financiamento.

A participação da mulher no mercado de trabalho brasileiro a partir dos anos 1970, a luta pelos movimentos sociais e a necessidade de ampliação do atendimento as crianças e as lutas pelo direito à educação alicerçadas pelo Estatuto da Criança e do Adolescente (ECA) de 1990 e pela Lei de Diretrizes e Bases da Educação Nacional, Lei n 9394/96 que define a educação infantil como dever do Estado. Apesar da fragmentação entre dois segmentos 0-3; 4-6 anos (Emenda Constitucional no 53/2006), não necessariamente no processo educativo, mas do ponto de vista da obrigatoriedade, a Lei $\mathrm{n}^{\circ} 11.700$, de 2008 , assegura vaga na escola pública de educação infantil mais próxima de sua residência para as crianças a partir dos 4 anos de idade. 
Esse corte etário estabelece a matrícula compulsória na educação básica das crianças a partir da idade pré-escolar e amplia a abrangência dos programas de atendimento à primeira infância (Emenda Constitucional n ${ }^{\circ}$ 59, de 2009). Dessa forma, espera-se que as redes públicas e escolas implementem o atendimento com equipamento específico para essa faixa etária e gradativamente amplie a oferta em horário integral. O que nos preocupa é que essa abrangência não se limite as tendências de socialização e a antecipação da escolarização:

a primeira tendência revela-se em práticas que destacam aspectos do desenvolvimento, tendo a 'socialização' e a formação de "hábitos, habilidades psicomotoras" como objetivos únicos ou principais; a segunda tendência se desenvolve em práticas com ênfase no treinamento, visando a escolarização posterior, pautando-se em ideias como a de prontidão (AQUINO; VASCONCELLOS, 2001, p. 179).

A educação infantil deve oferecer mais que socialização, precisa pautar-se no desenvolvimento das crianças promovendo o acesso ao conhecimento de acordo com a faixa etária a que se pretende atender através da contextualização em diferentes espaços, tempos e interações visando ampliar o universo cultural das crianças.

Nesse sentido, as Diretrizes Curriculares Nacionais de Educação Infantil (2009) propõem que as propostas pedagógicas respeitem os princípios éticos, estéticos e políticos. Os princípios éticos dizem respeito ao desenvolvimento da autonomia, da solidariedade, do respeito ao bem comum e a responsabilidade. Os princípios estéticos tratam da formação para o exercício da escuta sensível dos desejos das crianças negras, a criatividade e a diversidade. $\mathrm{E}$ os aspectos políticos determinam os direitos e deveres e ao exercício da cidadania através de "práticas de cuidado e educação na perspectiva da integração dos aspectos físicos, emocionais, afetivos, cognitivo/linguísticos e sociais da criança, entendendo que ela é um ser completo, total e indivisível" (DCNEI, 2009, p. 32, v. 2). Neste sentido é que defendemos uma educação da infância pautada nas práticas sociais e culturais de seu universo sociocultural mais amplo e que não se restrinja ao preparo para a escolarização ainda por vir.

\section{Breve panorama da Sociologia da Infância no Brasil}

Na Educação Infantil a Sociologia vem se configurando como Sociologia da infância enquanto um campo privilegiado para os estudos das diferentes culturas que representam as crianças e suas infâncias. Os estudos de Florestan Fernandes acerca das "trocinhas" do Bom Retiro contribuíram, significativamente, para a compreensão das culturas infantis, do folclore infantil brasileiro e suas múltiplas linguagens que nos revelam a compreender a importância 
do brinquedo como grupo social e sua natureza, portanto é a sociologia que esclarece o folclore. As "trocinhas" estão diretamente relacionadas ao desejo de brincar com os demais grupos infantis, assim iniciam as interações entres as crianças com o meio social (FERNANDES, 2004).

Abramowicz e Oliveira (2010) reconhecem que o trabalho de Florestan Fernandes desenvolvido em 1947 foi descrito pelos sociólogos foi pioneiro no Brasil ao retratar as crianças, sua infância e sua cultura. Nesse sentido, a Sociologia da Infância assume o lugar de reflexão para compreender a pesquisa com crianças e suas infâncias.

A Sociologia da Infância nos permite:

pensar a criança como sujeito e ator social do seu processo de socialização, e também construtores de sua infância, como atores plenos, e não apenas como objetos passivos deste processo e de qualquer outro. A partir desta primeira inflexão, outras foram realizadas e, dessa forma, permitiram o surgimento de novas temáticas, bem como a elaboração de novas metodologias que buscaram entender as crianças como produtoras de culturas, a partir delas próprias (ABRAMOWICZ; OLIVEIRA, 2010, p. 42).

Essa possibilidade inventiva de acolher a diferença e planejar temáticas que incorporem o discurso das crianças enquanto desafio de refletir sobre as nossas práticas e interpretar as relações entre as crianças desenvolve uma escuta sensível para:

entender o que as crianças falam, o que querem conhecer, o que há de interessante a fazer e a deixar de fazer, a estudar, deixar para lá; pensar o que há de interessante para visitar, que novas formas de brincar podem ser brincadas, que músicas e que danças podem ser inventadas. Talvez valha a pena aproveitar a ideia das cem linguagens preconizada pela escola italiana no interior de uma educação com a criança, no espaço público, em que as afectibilidades criem novas redes de solidariedade e pensamento para que se possibilite um devir criança (ABRAMOWICZ; LEVCOVITZ; RODRIGUES, 2009, p. 194).

Abramowicz e seus colaboradores apontam os fundamentos da Sociologia da Infância reconhecendo-a com área de conhecimento do campo de pesquisa que vem ampliando as possibilidades de interpretação dos saberes e interesses das crianças.

Entretanto, para compreensão desses saberes é necessário que nos tornemos professores reflexivos, sensíveis e vigorosos do ponto de vista da consistência de nossa formação, e esse processo pode se constituir ao longo de nossa trajetória profissional compartilhada numa perspectiva de uma comunidade investigativa (WELLS, 1994). 


\section{Saberes docentes e desenvolvimento profissional na Educação Infantil}

Para um maior aprofundamento das questões vinculadas ao nosso trabalho investigativo, entendendo ser necessário uma reflexão sobre os saberes constituídos pelos professores e professoras durante sua prática pedagógica e considerando que os saberes docentes representam um conjunto de estratégias, experiências de vida, validados pela sua atividade profissional. Sabemos que o trabalho reflexivo e de adensamento do professor das infâncias vai além da sala de atividades ao enfocar questões como trabalho, formação profissional, história de vida, relações entre cultura escolar e cultura dos professores - ao tecer a profissionalização como elementos da subjetividade, estabelecendo relações com os saberes e as práticas docentes. Os professores e as professoras constroem saberes que são mobilizados e produzidos a cada atividade, através da mediação da cultura e dos saberes escolares.

Assim, esse estudo pretende registrar a percepção dos professores, ou seja, a subjetividade de atores em ação assim como suas práticas cotidianas, buscando um diálogo com os professores como sujeitos competentes que possuem saberes específicos que contribuem para a Educação Infantil.

Segundo Tardif (2002), a subjetividade dos professores é desenvolvida a partir de três orientações inspiradas em pesquisas desenvolvidas na América do Norte e na Europa. A primeira orientação é uma visão cognitiva da subjetividade e faz parte da corrente das ciências cognitivas que colocam em evidência os processos mentais que regem o pensamento do professor em diversas situações: na gestão de classe, durante a transposição didática e na interação com as crianças. Na concepção americana, são utilizados os saberes procedimentais e instrumentais. Logo, o professor elabora as suas representações. Na percepção dos europeus, valoriza-se o processo de negociação em relação ao contexto de ensino.

A segunda orientação é uma visão existencial que caracteriza a "vida dos professores", isto é, a história de vida pessoal e profissional com enfoques narrativos que engloba suas experiências familiares, crenças, valores pessoais e a trajetória do professor. O trabalho assume uma dimensão afetiva, normativa e existencial, suas ações são marcadas pela sua própria experiência no trabalho. A sua autoridade é mediada pela sua relação pessoal com o grupo.

A terceira orientação é uma visão social, está pautada na vivência das crianças (VIGOTSKI, 2009; PRESTES; TUNES, 2012), e na etnometodologia (COULON, 1995) como estudo da linguagem comum ou cotidiana. Nesse sentido, os professores emitem um juízo de valor e normativo que definem as competências do professor dentro e fora da escola. 
Na Educação Infantil, compreendemos que o reconhecimento da história de vida do professor é relevante, pois poderá permitir uma maior aproximação entre o relacionamento com as crianças negras e valorizar as suas próprias experiências e, quando associadas a uma etnometodologia poderá explorar as questões do cotidiano como estímulo para a construção de seus saberes.

A reflexão sobre a formação de professores nos remete à prática pedagógica como condição essencial para que os educadores possam aperfeiçoar-se em conjunto com a sociedade. A formação de professores é um procedimento complexo que envolve saberes e uma preparação baseada na formação continuada, enquanto um movimento em que o conhecimento é apreendido, consolidado e internalizado para que haja uma troca de experiências, visando à função de educar

O educador deve compreender que a fonte de sua aprendizagem, de sua formação, é sempre a sociedade. Mas esta atua de dois modos: um, indiretamente, mas que aparece ao educando (futuro educador) como direito (pois é aquele que sente como ação imediata): é o educador, do qual recebe ordenadamente os conhecimentos. E outro, diretamente, ainda que apareça ao educando (futuro educador) como indireto, pois não o sente como pressão imediatamente perceptível: é a consciência, em geral com o meio natural e humano no qual se encontra o homem e do qual recebe os estímulos, os desafios, os problemas que o educam em sua consciência de educador (VIEIRA PINTO, 1984, p. 109-110).

Nesse contexto social, podemos ampliar a discussão sobre a formação de professores, partindo da formação inicial do professor de Educação Infantil, buscando ainda contemplar a especificidade desta modalidade.

A prática profissional dos professores (TARDIF, 2002) pode incentivar os professores comprometidos com o olhar diferenciado em perceber o interesse das crianças negras e suas especificidades, incentivando-os na direção de se tornarem profissionais práticos reflexivos. Esta condição individual e coletiva poderá contribuir para a construção de um Projeto político-pedagógico que atenda às necessidades das crianças negras, estabelecendo os principais temas que norteiem a prática pedagógica. Ou seja, sem um professor instrumentalizado em formação e percepção para atuar contra a discriminação e ela não combatida, as atividades na educação infantil terminam por reproduzir as discriminações raciais existentes em nossa sociedade. 


\section{Caminhos da pesquisa}

A Escola de Educação Infantil da Universidade Federal do Rio de Janeiro (EEI-UFRJ) foi inaugurada no dia 24 de junho de 1981, e desde então se localiza nas dependências do Instituto de Puericultura e Pediatria Martigão Gesteira (IPPMG). A partir do segundo semestre de 2013, o Conselho Universitário (Consuni) aprovou o processo de institucionalização da creche universitária "Pintando a Infância", que já se chamou Espaço de Educação Infantil e se afirma, atualmente, como a Escola de Educação Infantil da UFRJ, órgão suplementar do Centro de Filosofia e Ciências Humanas $(\mathrm{CFCH})$, em nível de equivalência com o CAP-UFRJ. Nesse sentido, “consideram-se Colégios de Aplicação, as unidades de educação básica que têm como finalidade desenvolver, de forma indissociável, atividades de ensino, pesquisa e extensão com foco nas inovações pedagógicas e na formação docente" (BRASIL, 2013). Assim como nos orientam a Resolução $\mathrm{n}^{\circ}$ 1, de 10 de março de 2011, que fixa normas de funcionamento das unidades de Educação Infantil ligadas à Administração Pública Federal direta, suas autarquias e fundações:

Art. 1. As unidades de educação infantil, mantidas e administradas por universidade federais, ministérios, autarquias federais e fundações mantidas pela União caracterizam-se, de acordo com o art. 16, inciso I, da Lei ${ }^{\circ}$ 9.394/96, como instituições públicas de ensino mantidas pela União, integram o sistema federal de ensino (BRASIL, 2011).

Nessa direção, a Escola de Educação Infantil está em pleno processo de incorporação ao CAP-UFRJ enquanto primeira etapa da educação básica. Atualmente, escola de educação infantil possui 80 crianças entre 4 meses a 5 anos de idade, sendo que destas, temos 15 crianças negras ou pardas, segundo a auto declaração presente no registro de matricula escolar.

A metodologia utilizada foi pesquisa qualitativa baseada em análise documental. Os documentos analisados as resoluções e pareceres do MEC e da universidade, além dos relatos registrados nos cadernos de planejamento onde os professores escrevem o seu cotidiano e a fala das crianças, referentes aos anos de 2013 a 2014. Na fase exploratória da pesquisa foram analisados 10 documentos que abordam as políticas e práticas docentes. Nossa principal preocupação e atenção foi a busca de casos descritos como sendo de discriminação racial e a partir daí a percepção e estratégia pedagógica adotada pelas professoras.

As professoras da EEI-UFRJ estão num continuo processo de formação continuada e, portanto, partimos do pressuposto de que qualquer situação discriminatória foi percebida por elas e descritas nos relatórios. O processo deste trabalho privilegiou a pesquisa sobre a 
infância das crianças negras enquanto sujeitos que produzem conhecimento, interessados em expressar sua cultura e seus saberes infantis. O desenvolvimento desta pesquisa leva em consideração que a realidade se encontra em permanente construção e que, por isso, o conhecimento e as ações se contextualizam em diferentes situações. Este processo reuniu as percepções e os saberes docentes, no esforço da elaboração de conhecimentos sobre aspectos da realidade significativos para o foco central deste trabalho: os conhecimentos mobilizados pelas professoras de Educação Infantil em sua prática pedagógica. As metodologias de pesquisa qualitativa são entendidas "como aquelas capazes de incorporar a questão do significado e da intencionalidade como inerentes aos atos, às relações, e às estruturas sociais, sendo essas últimas tomadas tanto no seu advento quanto na sua transformação, como construções humanas significativas" (MINAYO, 1999, p.10), considerando que uma análise qualitativa do material empírico possibilita uma discussão dialética ao contexto pedagógico.

A metodologia que utilizamos vincula-se a uma concepção de realidade, de mundo e de vida no seu conjunto. Este se constitui na mediação do processo de apreender, revelar e expor a estrutura, o desenvolvimento e a transformação dos fenômenos sociais.

Uma das especificidades da pesquisa qualitativa consiste na relação de dois importantes objetivos: o objetivo prático de contribuir para o equacionamento possível do problema central na pesquisa, enquanto um levantamento de soluções e propostas de ações que possam contribuir com os agentes na atividade transformadora da situação; e o objetivo de conhecimento, que visa obter informações que seriam de difícil acesso por meio de outros procedimentos, dada a sua natureza subjetiva das relações étnico-raciais entre as crianças, aumentando o conhecimento de determinadas situações tais como reivindicações, representações e capacidades de ação ou de mobilização. Na pesquisa associada ao processo de reconstrução, os elementos de tomada de consciência são levados em consideração tanto na própria situação investigada quanto, em particular, entre os docentes e na relação docentescrianças, sendo a tomada de consciência associada à própria geração de dados sob forma de questionamentos. Os nomes citados são fictícios para preservar a identidade das crianças.

Para a realização desta pesquisa, optamos pela utilização de uma revisão bibliográfica e análise dos documentos oficiais sobre a infância da criança negra e a educação infantil, considerando que o objeto e o sujeito não se constroem fora das relações históricas. As recentes publicações têm contribuído para a implementação das políticas públicas à promoção da igualdade social, ao respeito a diferença. Os aspectos sociológicos do conhecimento consideram as relações que fundamentam a organização social configurada pelas relações de produção de conhecimento, que tem como base a investigação científica na Educação Infantil. 


\section{O que se lê sobre relatos das professoras?}

O trabalho com o corpo através do jogo e da brincadeira merece destaque, pois é através do corpo infantil que o racismo se materializa na educação infantil, as práticas educativas precisam valorizar a escuta sensível e a observação cuidadosa que se refletem nas escolhas de seus pares no momento das brincadeiras, "o racismo, na pequena infância, incide diretamente sobre o corpo, na maneira pela qual ele é construído, acariciado ou repugnado" (OLIVEIRA; ABRAMOWICZ, 2010, p. 221-222). As cenas se refletem no cotidiano quando um bebê muito pequeno e negro passa pouco tempo no colo e chorando mais, do que uma criança branca que por vezes é mais "paparicada" pelas professoras, este, acaba desenvolvendo a estratégia de aprender a andar mais rápido que as demais; ou quando uma criança negra é preterida na organização e preparação para o banho em pequenos grupos. Uma professora comprometida com as questões étnico-raciais utiliza seu corpo de maneira expressiva e afetuoso, ou seja:

em cada gesto, no modo de olhar, sorrir, abraçar, pegar no colo, ele também constitui um modelo para as crianças, e por isso deve estar atento à intenção comunicativa e à qualidade de seus movimentos na interação com elas. É fundamental desenvolver atitudes que favoreçam o processo de desenvolvimento infantil, reconhecendo e validando os avanços e as conquistas de cada criança, estimulando a interação entre pares e crianças de diferentes faixas etárias. A tomada de consciência do próprio corpo pela criança, sua capacidade de perceber cada parte sem perder a noção de unidade, de conhecer e reconhecer a sua imagem como parte da construção de uma identidade positiva, requer um trabalho específico. O uso do espelho, desde o berçário, é um recurso importante para as crianças se reconhecerem, percebendo e identificando a imagem refletida como "sua" e como sendo bonita (SILVA; BENTO; CARVALHO, 2012, p. 31)

As professoras precisam estar disponíveis para ouvir as crianças, brincar no escorrega, correr, tomar banho no chuveirão junto com elas, participando e promovendo a interação das crianças negras no grupo. A organização do espaço escolar precisa privilegiar as produções das crianças incluindo ilustrações nos murais que envolvam a questão racial, as fotos das crianças e suas famílias, assim como os motivos da arte africana potencializam a autoestima das crianças negras.

\section{Considerações finais}

A pesquisa exploratória identificou uma demanda por um acervo de literatura infantil e estudos sociológicos sobre a infância da criança negra presentes na sala de leitura para que os 
adultos e as crianças possam se apropriar das questões que mobilizam o debate das relações étnico-raciais e para que os pequenos possam expressar e viver plenamente a sua infância.

A Escola de Educação Infantil da UFRJ embora seja um lugar privilegiado de educação de formação inicial e continuada, pois recebe os/as estudantes de Pedagogia para realizarem a prática de ensino e periodicamente, as suas professoras encontra-se em processos formativos. Nossa análise permite-nos considerar que primeiro precisamos ter uma valorização das relações étnico-raciais, o que uma demanda por encontros de formação continuada que potencializem os grupos de estudos e trocas de experiências com a participação dos movimentos sociais que dialoguem com a infância.

\section{REFERÊNCIAS}

ABRAMOWICS, A.; LEVCOVITZ, D.; RODRIGUES, T. C. Infâncias em Educação Infantil. Pro-Posições, Campinas, v. 20, n. 3 (60), p. 179-197, set./dez. 2009.

BOURDIEU, P. O poder simbólico. Rio de Janeiro: Bertrand Brasil, 2012.

BRASIL. Decreto $\mathbf{n}^{\circ}$ 93.408, de 10 de outubro de 1986. Dispõe sobre a instituição de creches e demais serviços de assistência pré-escolar para filhos de servidores dos órgãos e entidades da administração pública federal (Revogado pelo Decreto nº 997).

BRASIL. Lei no 8.069, de 13 de julho de 1990. Dispõe sobre o Estatuto da Criança e do Adolescente. Diário Oficial da União: República Federativa do Brasil: Poder legislativo Brasília, DF 1990. Disponível em: http://www.planalto.gov.br/ccivil_03/leis/18069.htm. Acesso em: 14 fev. 2020.

BRASIL. Decreto N 977, de 10 de setembro de 1993. Dispõe sobre a assistência pré-escolar destinada aos dependentes dos servidores públicos da Administração Pública Federal direta, autárquica e fundacional. Diário Oficial da União, Brasília, DF, 1993. Disponível em: http://www.planalto.gov.br/ccivil_03/decreto/Antigos/D0977.htm. Acesso em: 14 fev. 2020.

\section{BRASIL. Estatuto da Criança e do Adolescente, 1993.}

BRASIL. Ministério de Educação e Cultura. COEDI. Critérios para um atendimento em creches que respeite os direitos fundamentais das crianças. Brasília, 1995.

\section{BRASIL. Leis e Decretos. Lei de Diretrizes e Bases da Educação Nacional. Lei} n.9.394/1996. Brasília, 1996.

BRASIL. Lei ${ }^{\circ}$. 10.639 de 09 de janeiro de 2003. Inclui a obrigatoriedade da temática "História e Cultura Afro-Brasileira" no currículo oficial da rede de ensino. Diário Oficial da União: República Federativa do Brasil: Poder legislativo Brasília, DF 2003. Disponível em: http://www.planalto.gov.br/ccivil_03/leis/2003/110.639.htm. Acesso em: 14 fev. 2020. 
BRASIL. Emenda Constitucional No. 53, de 19 de dezembro de 2006. Dá nova redação aos arts. $7^{\circ}, 23,30,206,208,211$ e 212 da Constituição Federal e ao art. 60 do Ato das Disposições Constitucionais Transitórias. Diário Oficial da União, Brasília, DF, dez. 2006.

BRASIL. Lei n ${ }^{\circ} 11.700$ de13 de junho de 2008, garante vaga em escola pública de educação infantil ou de ensino fundamental próxima à residência. Diário Oficial da União: República Federativa do Brasil: Poder legislativo Brasília, DF jun. 2008. Disponível em:

http://www.planalto.gov.br/ccivil_03/_Ato2007-2010/2008/Lei/L11700.htm. Acesso em: 14 fev. 2020.

BRASIL. Emenda Constitucional n ${ }^{\circ}$ 59, de 11 de novembro de 2009. Prevê a obrigatoriedade do ensino de quatro a dezessete anos e ampliar a abrangência dos programas suplementares para todas as etapas da educação básica. Diário Oficial da União, Brasília, DF, nov. 2009. Disponível em: http://www.planalto.gov.br/ccivil_03/constituicao/Emendas/Emc/emc59.htm. Acesso em: 14

BRASIL. Ministério da Educação. Conselho Nacional de Educação. Câmara de Educação Básica. Resolução Nº 1, de 10 de março de 2011. Brasília, 2011.

CANCLINI, N. G. Culturas híbridas: estratégias para entrar e sair da modernidade. São Paulo: EDUSP, 2000.

CARVALHO, C. R.; Passos. M. C. P. Práticas, narrativas e memórias da diáspora: paisagens de uma pesquisa. 31 ${ }^{\mathrm{a}}$ Reunião Anual da ANPEd: Caxambu, MG, 2008.

CLADE. Consulta sobre la discriminación en la educación en la primera infancia: un estudio desde la perspectiva de la comunidad educativa en escuelas de Brasil, Perú e Colombia - Informe regional. São Paulo: CLADE, 2013.

FERNANDES, F. As "Trocinhas" do Bom Retiro: Contribuição ao Estudo Folclórico e Sociológico da Cultura e dos Grupos Infantis. In: Pro-Posições. v. 15, n. 1 (43), jan./abr. 2004.

GUIMARÃES, A. S. A. Democracia Racial: o ideal, o pacto e o mito. Novos Estudos, n. 61, p. 147-162, 2001.

GUIMARÃES, A. S. A. Classes, raças e democracia. São Paulo: fundação de Apoio a Universidade de São Paulo, ed. 34, 2002.

GUIMARÃES, A. S. A. Preconceito de cor e racismo no Brasil. Revista de Antropologia, São Paulo: USP, v. 47 n. 1, p. 9-41, 2004.

GUIMARÃES, A. S. A. Depois da democracia racial. Tempo Social, v. 18, n. 2, p. 269-287, nov. 2006.

GUIMARÃES, A. S. A. Preconceito racial: modos, temas e tempos. 2. ed. São Paulo: Cortez, 2012.

LE BRETON, D. As paixões ordinárias: antropologia das emoções. Petrópolis, Vozes. 2009. 
MINAYO, M. C. S. O desafio do conhecimento: pesquisa qualitativa em saúde. 6. ed. São Paulo: Hucitec; Rio de Janeiro: Abrasco, 1999.

MUNANGA, K. Negritude: usos e sentidos. $3^{\text {a }}$ Ed. Belo Horizonte: Autêntica, 2012.

OLIVEIRA, F.; ABRAMOWICS, A. Infância, raça e paparicação. Educ. Rev. (on line), v. 26, n. 2, p. 2-9-226, 2010.

PICCOLO, G. M. Educação Infantil: análise social do preconceito na atividade principal de jogos. Educação e Sociedade, Campinas, v. 32, n. 114, p. 205-221, jan.-mar. 2011.

PRESTES, Z.; TUNES, E. A trajetória de obras de Vigotski: um longo percurso até os originais. Estudos de Psicologia I, Campinas I 29(3) I 327-340 I julho - setembro 2012.

ROSEMBERG, F. A criança pequena e o direito à creche no contexto dos debates sobre infância e relações raciais. In: BENTO, M. A. S. (org.). Educação infantil, igualdade racial e diversidade: aspectos políticos, jurídicos, conceituais. São Paulo: Centro de Estudos das Relações de Trabalho e Desigualdades - CEERT, 2012.

SILVA JR., H.; BENTO, M. A.; CARVALHO, S. Educação Infantil e práticas promotoras de igualdade racial. São Paulo: Centro de Estudos das relações de Trabalho e Desigualdades - CEERT: Instituto Avisa Lá - Formação Continuada de Educadores, 2012.

SOVIK, L. Aqui ninguém é branco. Rio de Janeiro: Aeroplano editora, 2009.

TARDIF, M. Saberes docentes e formação profissional. 2. ed. Petrópolis, RJ: Vozes, 2002.

TRINIDAD, C. T. Identificação étnico-racial na voz de crianças em espaços de educação infantil. Orientadora: Cláudia Leme Ferreira Davis. 2011. Tese (Doutorado). Pontifícia Universidade Católica de São Paulo, Psicologia da Educação. São Paulo, 2011. Disponível em: https://tede2.pucsp.br/handle/handle/15994. Acesso em: 14 fev. 2020.

VIEIRA PINTO, A. Sete lições sobre educação de adultos. 2. ed. São Paulo: Autores Associados/Cortez, 1984.

VIGOTSKI, L. S. Imaginação e criação na infância. Madrid São Paulo: Editora Ática, 2009.

WELLS, G. La Formación del Maestro Investigativo, mimeo., 1994. 


\section{Como referenciar este artigo}

FERREIRA, E. dos S.; VIEIRA, J. J.; VIEIRA, A. L. C. Relações étnico-raciais e saberes docentes na Escola de Educação Infantil da Universidade Federal do Rio de Janeiro. Revista Ibero-Americana de Estudos em Educação, Araraquara, v. 15, n. 1, p. 236-252, jan./mar. 2020. e-ISSN: 1982-5587. DOI: https://doi.org/10.21723/riaee.v14i4.10006

Data de Submissão: 25/06/2017

Revisões Requeridas: 30/11/2017

Aceite em: 20/05/2019

Publicado em: 02/01/2020 